\title{
Ensaio não destrutivo em revestimento cerâmico utilizando um protótipo para detecção de patologia
}

\author{
Non destructive test in ceramic coating using \\ a prototype for detection of pathology
}

\author{
Diogo Florencio Pessanha ${ }^{1}$, Jonas Alexandre ${ }^{1}$, Jose Augusto Pedro Lima ${ }^{1}$, \\ Afonso Rangel Garcez de Azevedo ${ }^{1}$, Euzébio Bernabé Zanelato ${ }^{1}$
}

\begin{abstract}
${ }^{1}$ Universidade Estadual do Norte Fluminense - UENF, Programa de Pós-Graduação em Engenharia Civil - PPGEC, Avenida Alberto Lamego 2000, 28013-602, Campos dos Goytacazes, Rio de Janeiro, Brasil. e-mail: diogofpessanha@hotmail.com, jonas@uenf.br, japlima@uenf.br, afonso.garcez91@gmail.com, ebzanelato@gmail.com
\end{abstract}

\section{RESUMO}

No setor da construção civil há um crescente investimento na manutenção e reparo das construções, como por exemplo, as patologias encontradas nos pisos com revestimento cerâmico. Dentre as patologias mais comuns se pode destacar o assentamento inadequado das placas cerâmicas, que são caracterizadas pela perda de aderência de algumas placas a sua base de assentamento (substrato). Devido à probabilidade de acidentes envolvendo os usuários e os elevados custos de reparo, esta é considerada uma importante patologia. Este trabalho tem o objetivo de apresentar uma nova metodologia de ensaio não destrutivo, baseado no desenvolvimento de uma ferramenta fundamentada na resposta cinética e acústica de um protótipo, que ao percutir uma placa cerâmica com perda de aderência produz um som cavo e uma perda significativa de energia, permitindo identificar a ocorrência desta patologia. Utilizou-se seis tipos de pisos cerâmicos assentados em conformidade e em não conformidade com a norma brasileira, e em seguida, houve a determinação dos coeficientes de restituição de cada pisos. Os sons dos impactos nas placas também foram captados por um microfone dinâmico e um captador piezoelétrico e processados por meio do programa Realtime Analyzer, que produz gráficos que relacionam frequência, amplitude, energia sonora e tempo. Os resultados obtidos pelo protótipo foram comparados com outros quatro métodos não normatizados: cabo de madeira, barra roscada, barra de aço e esfera metálica. Concluiu-se que o uso do protótipo desenvolvido é viável para a detecção de patologia de assentamento das placas cerâmicas, revelando ser uma estratégia preventiva e não destrutiva.

Palavras-chave: revestimento cerâmico, patologia, protótipo, impacto.

\section{ABSTRACT}

In the construction sector there is a growing investment in the maintenance and repair of constructions, such as the pathologies found on floors with ceramic coating. Among the most common pathologies, it is possible to highlight the inadequate seating of the ceramic floor, which are characterized by the loss of adhesion of some plates to their base (substrate). Due to the probability of accidents involving users and the high costs of repair, this is considered an important pathology. The objective of this work is to present a new nondestructive test methodology, based on the development of a tool based on the kinetic and acoustic response of a prototype, which, when a ceramic floor with the loss of adhesion is produced, produces "cavo" sound and a significant loss of to identify the occurrence of this pathology. Six types of ceramic flooring were used, in compliance and in conformity with the Brazilian standard, and then the coefficients of restitution of each plate were determined. The impact sounds on the boards were also picked up by a microphone and a piezoelectric pickup and processed through the Realtime Analyzer program, which produces charts that relate frequency, amplitude, sound energy, and time. The results obtained by the prototype were compared to other non-standard methods: wood rod, threaded rod, steel bar and metal sphere. It was concluded that the prototype is feasible for the detection of pathology of settlement of ceramic floor, proving to be a preventive and non-destructive strategy.

Keywords: ceramic, pathology, prototype, impact. 


\section{INTRODUÇÃO}

Na construção civil, os revestimentos cerâmicos continuam a ser amplamente utilizados, pois oferecem elevada durabilidade, bom desempenho técnico e vastas possibilidades estéticas. Apesar da evolução da indústria e dos métodos de fixação, continuam enfrentando variados problemas patológicos [1], que são originadas por problemas variados, como erros de execução da argamassa colante, assentamento incorreto das placas além de problemas relacionados ao uso [2].

A ocorrência de patologias em revestimentos cerâmicos diminui a vida útil de uma construção e provoca a sua progressiva degradação, resultando em trabalhos de recuperação desagradáveis aos usuários e custos adicionais que poderiam ser evitados. $\mathrm{O}$ mal assentamento de placas cerâmicas gera destacamento de placas, que é uma patologia observada pela separação lenta e progressiva de algumas peças de sua base de assentamento. Quando as placas cerâmicas vão se desprendendo, mas ainda permanecem parcialmente unidas pelo rejunte, há a emissão de um som cavo quando percutidas por algum objeto, o que gera incomodo aos usuários, tornando-se um problema patológico. A recuperação desta patologia é muito onerosa e trabalhosa, onde muitas vezes a solução é a troca de todo o revestimento [3].

A necessidade de inspecionar e diagnosticar as anomalias existentes em construções nos leva a adotar procedimentos que permitam verificar algumas patologias, antes mesmo dessas se manifestar, reduzindo assim os possíveis impactos aos usuários. Essa investigação deve ser eficaz e preferencialmente não destrutiva, reduzindo os custos desse processo [4].

As normas brasileiras NBR 9817 (1987) [5] e 13.753 (1996) [6] fixam as condições exigíveis para a execução, fiscalização e recebimento de piso de revestimento cerâmico, ambas afirmam que os ensaios devem ser feitos após três dias do assentamento e antes da colocação do rejuntamento, define ainda que "a aderência dos pisos cerâmicos à argamassa de assentamento deve ser examinada em toda a extensão e que nenhum piso cerâmico deve produzir som cavo, quando percutido por instrumento não contundente", surgindo assim a necessidade de metodologias analíticas para esse processo.

A indicação da norma brasileira ainda indica que o instrumento utilizado para a detecção do som emitido deve ser metálico, porém não fornece informações de como seria esse instrumento metálico não contundente, surgindo assim uma demanda por normatização deste instrumento [5].

As argamassas utilizadas para assentamento de placas cerâmicas, que podem ser para pisos cerâmicos ou revestimento de paredes, devem ter uma série de características no estado fresco, que visem uma maior aderência entre o substrato e a placa, evitando aparecimento de patologias [7].

Em um estudo realizado em algumas obras localizadas no interior do estado do Rio de Janeiro, foi verificado com os profissionais responsáveis pela colocação das placas cerâmicas que a metodologia utilizada para verificação de não conformidades dos revestimentos em geral eram cabos de madeira, barra roscada ou barras de aço, sem nenhum processo normatizado, baseando-se em situações empíricas. A metodologia utilizada na obra em questão baseia-se em soltar tais objetos de uma determinada altura, não padronizada, em direção ao revestimento e verificar o tipo de som gerado a partir do impacto, entre o objeto lançado e o revestimento [8].

Estudos relativos a ensaios patológicos em revestimentos cerâmicos em geral destinam-se a metodologias destrutivas, como ensaios de arrancamento de placas, que geram grandes danos as edificações, além de elevados custos. Um dos grandes problemas destas metodologias refere-se a dificuldade de se encontrar um revestimento idêntico ao danificado para reposição, o que gera quando transtornos aos usuários [1]. Quando se fala em metodologias não-destrutivas para revestimentos algumas técnicas muito usadas em estruturas de concreto, como ultrassom, raio-X e outras podem ser utilizadas, e já foram objeto de estudos [3,7]. Entretanto todas essas técnicas são de elevado custo financeiro e apresentam dificuldades de execução em um canteiro de obras. Assim o desenvolvimento de uma metodologia mais simples e prática revela-se altamente promissora na construção civil.

Com intuito de detectar a perda de aderência dos revestimentos cerâmicos aos substratos, patologia de maior incidência nos revestimentos [7], este trabalho tem como objetivo apresentar um modelo de protótipo padronizado, que seja de fácil manuseio e baixo custo, possibilitando seu amplo uso na construção civil. Assim para verificar a validação do protótipo, primeiramente reproduziu-se os defeitos de mal assentamento, comparando-o com revestimentos assentados adequadamente. Realizou-se também um comparativo com as principais técnicas utilizadas para detecção dessa patologia. 


\section{MATERIAIS E MÉTODOS}

\subsection{Materiais empregados para confecção do protótipo e seu funcionamento}

O protótipo elaborado apresenta fácil manuseio e sua estrutura é de um tripé sustentando-o sobre os revestimentos cerâmicos. Este protótipo é constituído pelos seguintes materiais:

- Quatro barras roscadas de 1/4" x $1 \mathrm{~m}$ de aço carbono;

- Seis elásticos de borracha $\mathrm{n}^{\circ} 18$ de constante elástica $200 \mathrm{~N} / \mathrm{m}$;

- Dois suportes de acrílico na forma de triângulo equilátero vazado com arestas externas de $17 \mathrm{~cm} \mathrm{e}$ interna de $7 \mathrm{~cm}$;

- Doze porcas sextavada de 1/4" de aço carbono.

As três barras das extremidades são fixadas nos suportes de acrílico por meio das porcas que as mantêm imóveis. A barra roscada central é móvel e fica equilibrada por elásticos, permitindo apenas movimentos ascendentes e descendentes. Os elásticos têm a função de centralizar e sustentar a barra móvel, além de servirem de força restauradora nos movimentos ascendentes e descendentes. A estrutura do protótipo é representada na Fig.1:
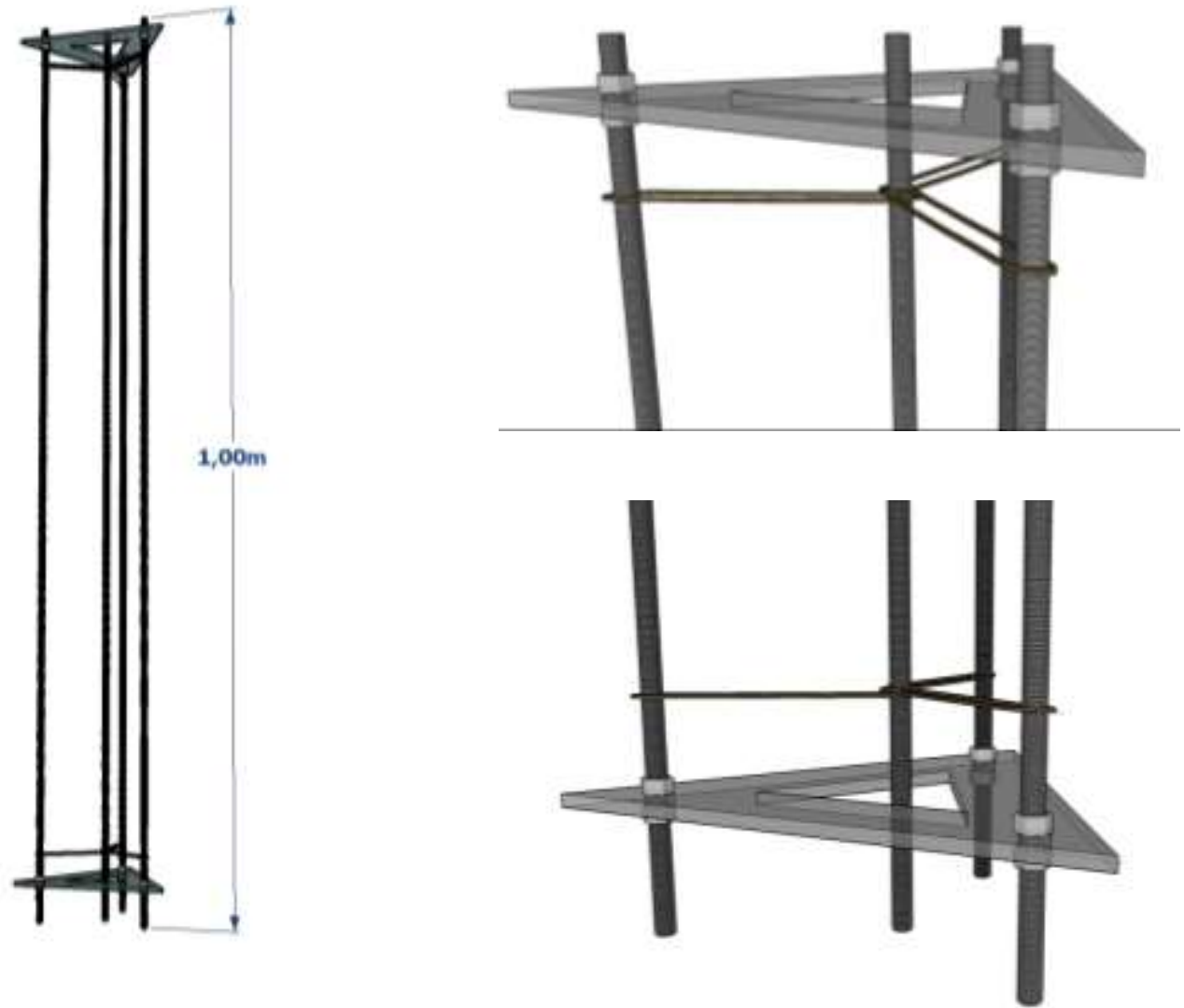

Figura 1: Imagem do protótipo.

O funcionamento do protótipo ocorre acionando os dois movimentos: o primeiro de suspensão pelo ato de pinçar dos dedos polegar e indicador (Fig.2a) e o segundo, de liberação (Fig.2b). Considere um sistema com uma barra vertical de massa $m$ e tamanho $l$ livre e em repouso, equilibrada por um amortecedor elásticos de constante elástica $k$, que se encontra apoiada em uma superfície horizontal rígida. Suponha que a barra sofra um deslocamento ascendente para a posição $X_{1}$ (Fig.2c). Por consequência desse movimento, haverá um desequilíbrio no amortecedor elástico, visto que ao liberar a posição de deformação $X_{1}$ o amortecedor tentará se restabelecer, ou seja, voltar para a posição inicial 0 (Fig.2d). 


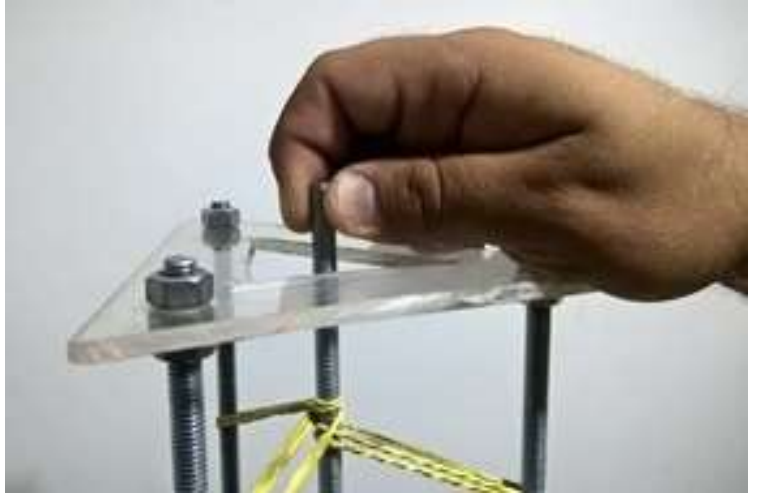

a)

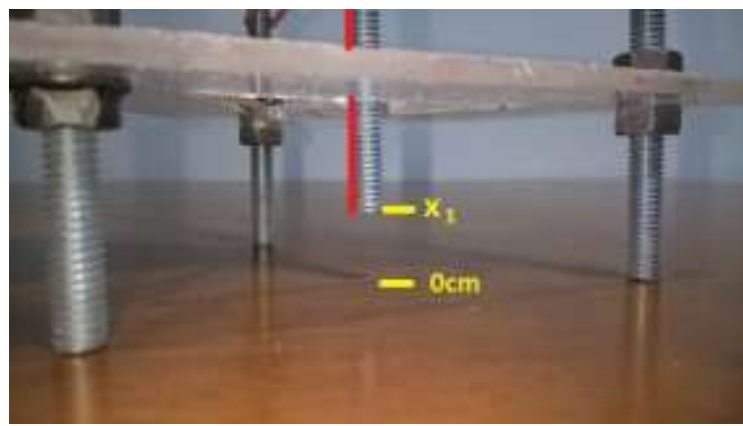

c)

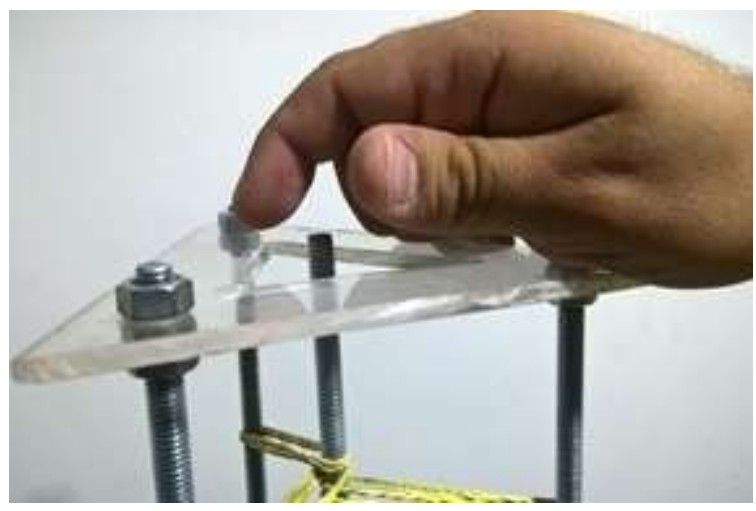

b)

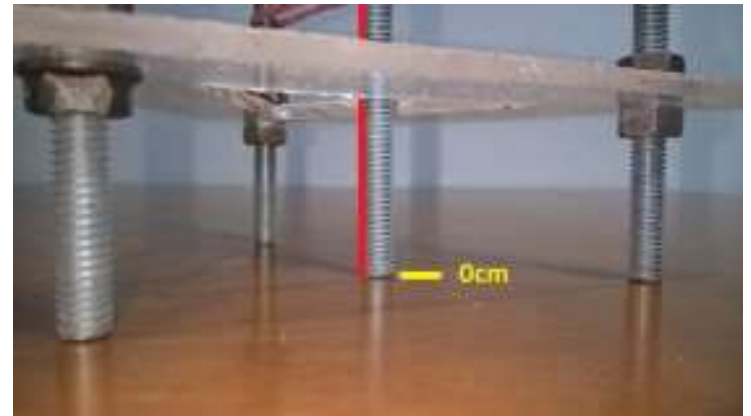

d)

Figura 2: Funcionamento do protótipo: a) movimento ascendente da barra, b) movimento descendente da barra, c) deslocamento para a posição $\mathrm{X}_{1} \mathrm{e}$ d) posição inicial.

Durante o processo de liberação, ou seja, na posição $\mathrm{X}_{0}$ ocorre uma conversão da energia potencial gravitacional e elástica em cinética até que ocorra o choque com a superfície horizontal. Durante esse choque atuará uma força impulsiva que inverte o sentido do vetor velocidade e, por conseguinte, do momento linear da barra. Posteriormente, ao iniciar um movimento ascendente, a energia cinética vai se convertendo em energia potencial e se anula quando a partícula alcança a posição um pouco menor do que a altura de onde foi solta. A barra não retornará à posição inicial de deformação, pois parte da energia é dissipada [9].

A dissipação de energia se deve a ondas de choque e a perda térmica associada ao impacto dos dois corpos [10]. Pelo modelo genérico de impacto elástico de Hertz [11] quando uma barra rígida se choca com o piso, o impacto gerado produz ondas de choques na região da colisão, cuja propagação se irradia no material a partir do contato, ao encontrar uma superfície livre ou outro material de impedância de choque de valor diferente, a onda de compressão gerada pelo impacto reflete como uma onda trativa diminuindo o coeficiente de restituição.

\subsection{Assentamento de pisos}

Para o assentamento das placas cerâmicas, fez-se necessário a execução de um substrato, que se assemelhasse com as condições reais, uma laje de concreto armado. Assim foram confeccionadas bases, com a seguinte metodologia:

1 - Concretagem de 12 bases $60 \times 60 \mathrm{~cm}$ com espessura de $7 \mathrm{~cm}$. Todas as bases de concreto com resistência à compressão média de 32,5 MPa aos 28 dias.

2 - Após os 28 dias, confecção do contrapiso de espessura de $2 \mathrm{~cm}$ com argamassa com proporção 1:6 (cimento: areia, em volume) conforme a NBR 13.753(1996) [6]. Para confecção do contrapiso utilizou-se uma forma padrão em madeira de 59 x $59 \mathrm{~cm}$ e espessura $2 \mathrm{~cm}$.

3 - Depois de uma semana utilizou-se a desempenadeira dentada para fazer os cordões na argamassa colante do tipo ACII.

4 - Assentamento de seis tipos de placas cerâmicas diferentes, assentados com e sem patologias, totalizando 12 placas cerâmicas. As características dos pisos e sua nomenclatura estão apresentadas na Tab.1. 
Tabela 1: Nomenclatura e características das placas cerâmicas assentadas com e sem patologia.

\begin{tabular}{c|c|c|c|c|c|c|c|c}
\hline Piso & $\begin{array}{c}\text { Piso sem } \\
\text { patologia }\end{array}$ & $\begin{array}{c}\text { Piso com } \\
\text { patologia }\end{array}$ & $\begin{array}{c}\text { Dimensões } \\
\mathbf{c m} \mathbf{~ c m}\end{array}$ & $\begin{array}{c}\text { Espessura } \\
\mathbf{m m}\end{array}$ & \multicolumn{2}{|c|}{ Grupo de absorção } & $\begin{array}{c}\text { Natureza da } \\
\text { Superfície }\end{array}$ & $\begin{array}{c}\text { Classe de } \\
\text { abrasão }\end{array}$ \\
\hline P1 & P1s & P1c & $50 \times 50$ & 7,2 & BIIb & Semi-poroso & Esmaltada & PEI 4 \\
\hline P2 & P2s & P2c & $45 \times 45$ & 7,2 & BIIb & Semi-poroso & Esmaltada & PEI 4 \\
\hline P3 & P3s & P3c & $54 \times 54$ & 8,2 & BIa & Porcelanato & Esmaltada & PEI 4 \\
\hline P4 & P4s & P4c & $36 \times 26$ & 7,4 & BIlb & Semi-poroso & Esmaltada & PEI 3 \\
\hline P5 & P5s & P5c & $45 \times 45$ & 6,5 & BIIb & Semi-poroso & Esmaltada & PEI 4 \\
\hline P6 & P6s & P6c & $45 \times 45$ & 6,5 & BIIa & Semi-gres & Esmaltada & PEI 4 \\
\hline
\end{tabular}

No assentamento da placa cerâmica sem patologia a colocação das placas ocorreu uma de cada vez, ligeiramente fora de posição, sobre os cordões de cola. A colagem foi dupla, ou seja, no piso e na base. Utilizou-se uma desempenadeira de 8 × 8 × 8 mm em conformidade com a NBR 13.753 (1996) [6]. Em seguida, sucedeu a fixação do revestimento cerâmico por meio de um ligeiro movimento de rotação. Realizou-se leves batidas com um martelo de borracha sobre a face da cerâmica. Nesse processo, os revestimentos cerâmicos foram assentados individualmente em seis blocos, para sua identificação optou-se por atribuir a nomenclatura "Ps-Placa cerâmica sem patologia".

Para induzir o aparecimento de patologias, o assentamento das placas cerâmicas ocorreu em discordância do que exige a norma, com tempo em aberto de três horas. A desempenadeira utilizada foi a de $6 \times 6 \times$ $6 \mathrm{~mm}$ e não houve colagem dupla, ou seja, somente colagem na base. Nesse processo foram assentados os revestimentos cerâmicos individualmente em seis blocos, para sua identificação optou-se por atribuir a nomenclatura "Pc-Placa cerâmica com patologia".

\subsection{Ensaio do coeficiente de restituição}

Alguns trabalhos utilizaram esferas na determinação do coeficiente de restituição, e afirmaram que o coeficiente de restituição diminui à medida que os diâmetros e velocidade das bolas aumentavam, pois esses estão ligados diretamente na energia de impacto $[13,14]$. Considerando essa informação e para simplificar o experimento decidiu-se para essa pesquisa usar uma esfera de tamanho padrão de $10 \mathrm{~mm}$ de diâmetro, massa de $5,3 \mathrm{~g}$ e altura de lançamento de $1 \mathrm{~m}^{1}$.

Obteve-se o valor da energia da esfera através da Equação 1 ( $\mathrm{E}_{\mathrm{Pg}}$; energia potencial gravitacional), onde se considerou a aceleração da gravidade ${ }^{2} g$ com valor aproximado de $9,79 \mathrm{~m} / \mathrm{s}^{2}$.

$$
E_{P g}=m g h
$$

Onde $m$ é a massa e $h$ a altura.

Considerando a energia da esfera de patamar (0,052 J) e utilizando a decomposição da equação 1 , resulta-se a Equação 2, sendo possível calcular a altura da barra de aço, da barra roscada e do cabo de madeira. Estes materiais foram medidos na balança analítica cujos resultados se apreentam na Tab. 2.

$$
h_{1}=\frac{E_{p g}}{m \cdot g}
$$

Onde $E_{p g}$ é a energia potencial gravitacional, $m$ é a massa e $g$ é a aceleração da gravidade.

Para calcular a altura do protótipo além da Equação 1, também se utilizou a Equação 3 ( $E_{\mathrm{Pe}}$ energia potencial elástica) e igualou-se a energia de patamar da esfera.

\footnotetext{
${ }^{1}$ Essa altura é a mesma utilizada pela a ISO 10545-5:2002 [15], mas a esfera é de 19mm, a qual não foi encontrada no mercado local.

2 Aceleração da gravidade local através da utilização do GPS $9.78743 \mathrm{~m} / \mathrm{s}^{2}$.
} 


$$
E_{P e}=\frac{k x^{2}}{2}
$$

Sendo que, $K$ a constante elástica do sistema de amortecimento e $x$ é a deformação.

Considerando a lei de conservação de energia mecânica, a deformação do sistema de elástico do protótipo será a mesma da altura, logo a deformação é igual a $\mathrm{h}_{1}$, chegando a uma equação de segundo grau (Equação 4):

$$
\frac{k h_{1}^{2}}{2}+m g h_{1}=0,052
$$

Sendo a constante elástica do sistema $\mathrm{k}=200 \mathrm{~N} / \mathrm{m}$, resulta o polinômio:

$$
100 h^{2}+4 h_{1}-0,052=0
$$

Resolvendo este polinômio de segundo grau obteve-se a altura de deformação do protótipo.

A Tab.2 apresenta as massas e as alturas relacionadas a cada método, de forma a igualar a energia para o lançamento da esfera da distância de um metro de altura.

Tabela 2: Valores da massa e altura aproximada para um mesmo valor de energia.

\begin{tabular}{c|r|r|r}
\hline Objeto de ensaio & Massa (kg) & \multicolumn{1}{|c|}{ Altura (m) } & \multicolumn{1}{|c}{ Energia (J) } \\
\hline Esfera & 0,0053 & 1,00 & 0,052 \\
\hline Barra de aço & 0,2161 & 0,025 & 0,052 \\
\hline Barra roscada & 0,1544 & 0,034 & 0,052 \\
\hline Cabo de Madeira & 0,2107 & 0,025 & 0,052 \\
\hline Protótipo & 0,411 & 0,010 & 0,052 \\
\hline
\end{tabular}

A Fig. 3 apresenta um esboço do arranjo experimental adaptado de HORABIK et al [16], Li et al [17] e ISO 10545-5 [15], equipada com três câmeras de vídeo (câmera 1, câmera 2 e câmera 3). Utilizou-se a Câmera 1 para a medição da altura de rebote $\mathrm{h}_{2}$, já a câmera 2 foi utilizada unicamente para determinação da distância x' do método da esfera, e para a distância de rebote $\mathrm{h}_{2}$ dos outros métodos utilizou-se a câmera 3.

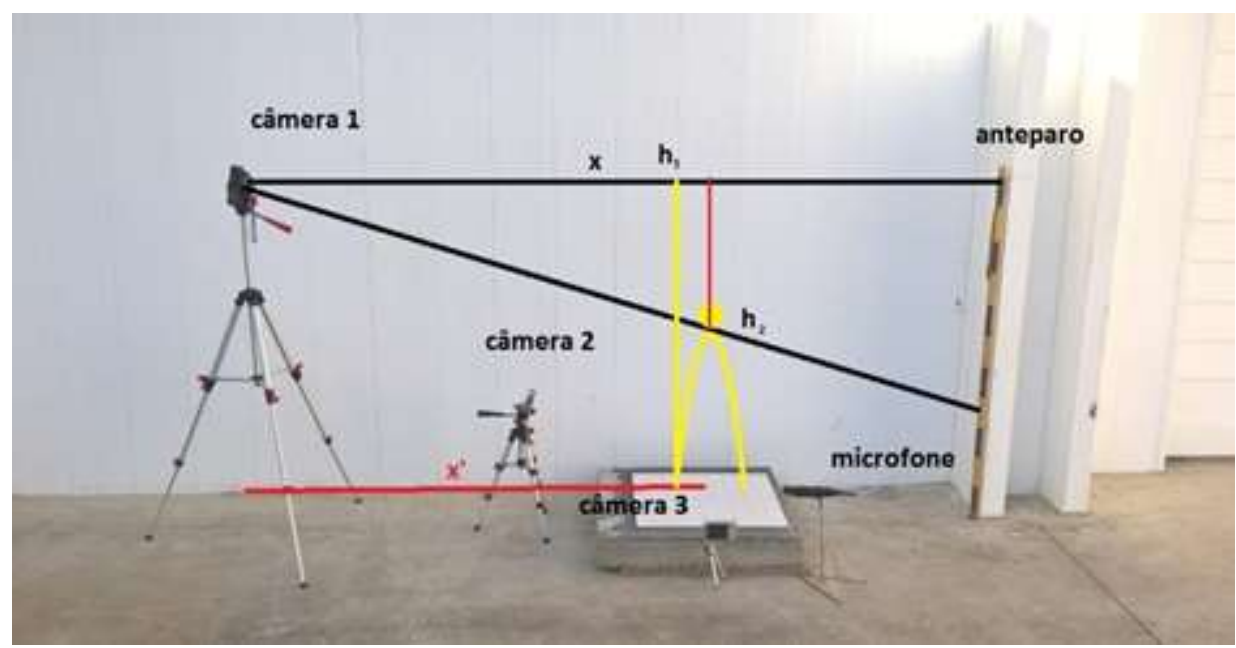

Figura 3: Esquema mostrando as trajetórias da esfera, posição inicial altura $h_{1}\left(\right.$ antes) e posição depois altura $h_{2}$ (final) da colisão com o piso. 
Com a proporção entre $\mathrm{X} h_{1}$ e x' $h_{2}$ é possível chegar a equação 6 e calcular o coeficiente de restituição.

$$
h_{2}=\frac{h_{1} x^{\prime}}{X}
$$

\subsection{Captura do som}

Para captar o som, utilizou-se um microfone dinâmico e um captador piezoelétrico de $35 \mathrm{~mm}$. O primeiro foi instalado a uma distância fixa de $50 \mathrm{~cm}$ em diagonal do centro de cada placa em todos os ensaios. Já o captador piezoelétrico foi instalado no vértice da placa, ilustrado na Fig. 4. Na ocorrência do impacto, um som audível é produzido. Em cada impacto, foi utilizado o software licenciado Realtime Analyzer, para a realização da leitura das bandas de frequências dos sons.

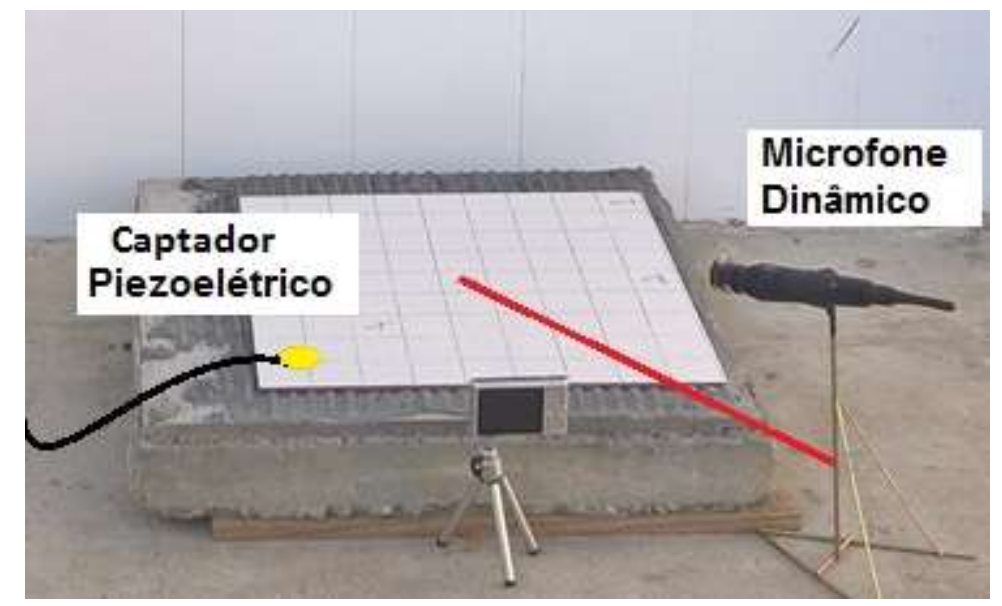

Figura 4: Exemplo da localização do microfone dinâmico e do captador piezoelétrico em relação aos blocos.

\section{RESULTADOS}

\subsection{Comparativo dos métodos: coeficiente de restituição}

Para o comparativo entre os métodos analisou-se os coeficientes de restituição e pico de frequência para uma mesma energia de cinco modelos: Cabo de madeira (Fig. 5a); Barra de aço (Fig. 5b); Barra roscada (Fig. 5c); Esfera metálica (Fig. 5d); Protótipo (Fig. 5e). 


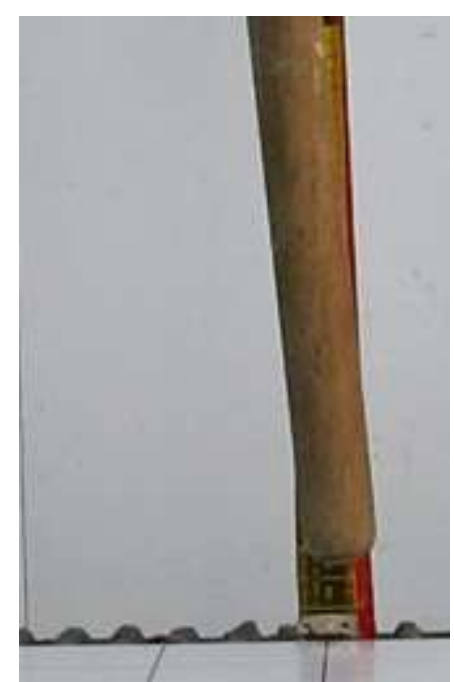

a)

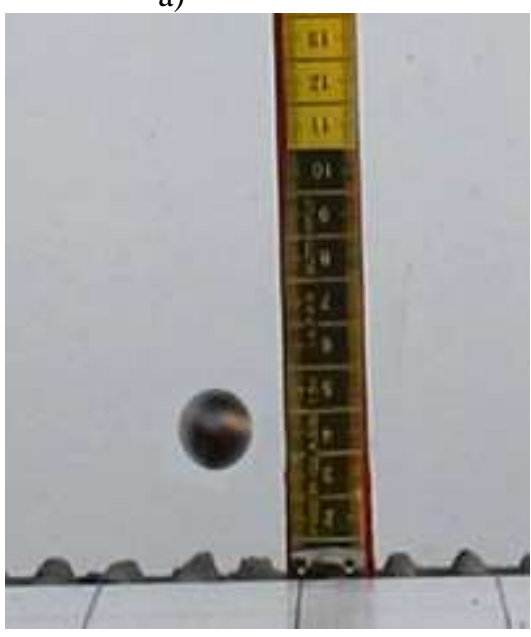

d)

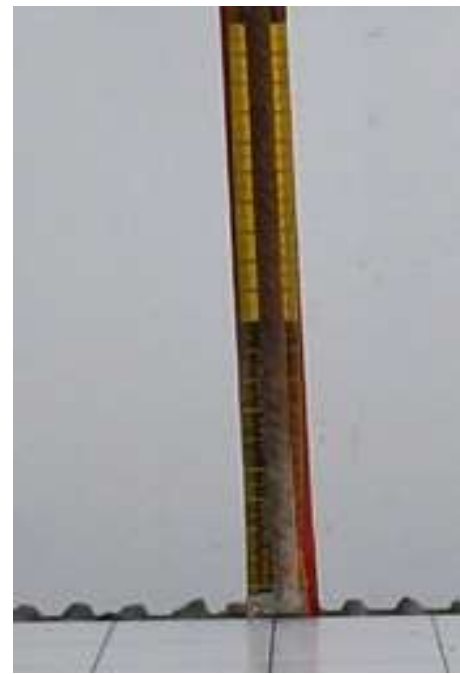

b)

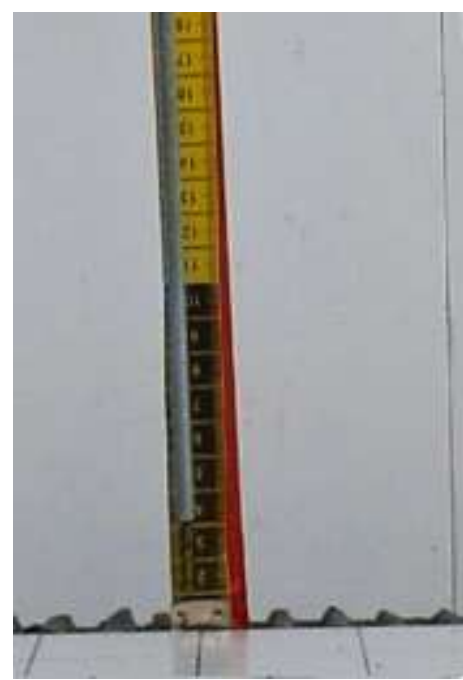

c)

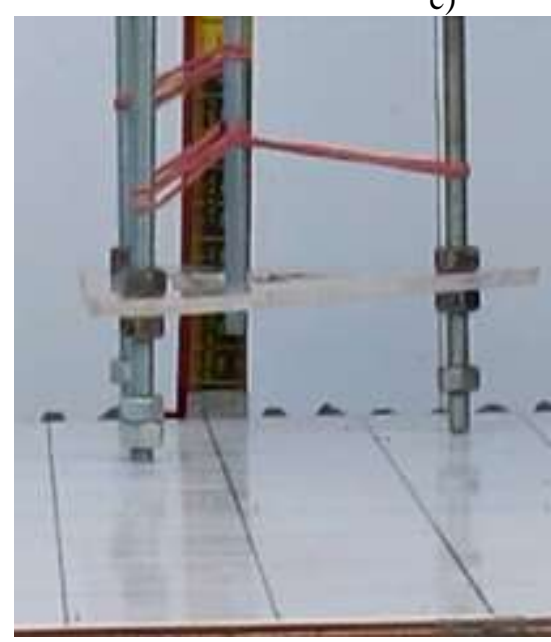

e)

Figura 5: Captura da câmera 3 dos materiais em análise: a) cabo de madeira, b) barra de aço, c) barra roscada, d) esfera metálica, e) protótipo.

Nesse comparativo utilizaram-se placas cerâmicas com e sem patologia e para determinar a altura de lançamento dos objetos, considerou-se a energia da esfera metálica lançada de $1 \mathrm{~m}$ de altura como patamar referencial. Lançando os objetos das alturas determinadas para a energia de patamar, foi possível obter os coeficientes de restituição por meio da Equação 7.

$$
e=\sqrt{\frac{h_{2}}{h_{1}}}
$$

A Tab. 3 apresenta os resultados da média dos coeficientes de restituição em pisos sem patologia e a Tab. 4 em pisos com patologia.

Tabela 3: Representação dos coeficientes de restituição referente a uma energia de patamar pré-estabelecida para os pisos sem patologia.

\begin{tabular}{c|c|c|c|c|c}
\hline $\begin{array}{c}\text { Média do } \\
\text { Coeficiente de } \\
\text { Restituição }\end{array}$ & $\begin{array}{c}\text { Cabo de } \\
\text { madeira }\end{array}$ & $\begin{array}{c}\text { Barra de } \\
\text { aço }\end{array}$ & $\begin{array}{c}\text { Barra } \\
\text { roscada }\end{array}$ & Esfera & Protótipo \\
\hline $\mathrm{P} 1 \mathrm{~s}$ & 0,40 & 0,44 & 0,43 & 0,68 & 0,46 \\
\hline $\mathrm{P} 2 \mathrm{~s}$ & 0,42 & 0,47 & 0,46 & 0,65 & 0,47 \\
\hline
\end{tabular}




\begin{tabular}{c|c|c|c|c|c}
\hline P3s & 0,50 & 0,55 & 0,56 & 0,79 & 0,60 \\
\hline P4s & 0,45 & 0,50 & 0,51 & 0,72 & 0,50 \\
\hline P5s & 0,39 & 0,43 & 0,44 & 0,65 & 0,43 \\
\hline P6s & 0,38 & 0,44 & 0,45 & 0,67 & 0,44 \\
\hline
\end{tabular}

Tabela 4: Representação dos coeficientes de restituição referente a uma energia de patamar pré-estabelecida para os pisos com patologia.

\begin{tabular}{c|c|c|c|c|c}
\hline $\begin{array}{c}\text { Média do } \\
\text { Coeficiente de } \\
\text { Restituição }\end{array}$ & $\begin{array}{c}\text { Cabo de } \\
\text { madeira }\end{array}$ & $\begin{array}{c}\text { Barra de } \\
\text { aço }\end{array}$ & $\begin{array}{c}\text { Barra } \\
\text { roscada }\end{array}$ & Esfera & Protótipo \\
\hline P1c & 0,25 & 0,3 & 0,31 & 0,50 & 0,33 \\
\hline P2c & 0,27 & 0,31 & 0,32 & 0,51 & 0,37 \\
\hline P3c & 0,40 & 0,43 & 0,45 & 0,65 & 0,43 \\
\hline P4c & 0,31 & 0,35 & 0,36 & 0,57 & 0,38 \\
\hline P5c & 0,26 & 0,29 & 0,30 & 0,51 & 0,27 \\
\hline P6c & 0,26 & 0,30 & 0,31 & 0,52 & 0,31 \\
\hline
\end{tabular}

Analisando e comparando os dados das Tab. 3 e 4, comprova-se que os pisos com patologia apresentam menores coeficientes de restituição em relação aos pisos sem patologia, isso ocorre, pois, ao impactar objetos as ondas de choque sofrem interferência, dessa forma a energia é dissipada no choque sendo consumida pela energia sonora e térmica [18].

\subsection{Comparativo dos métodos: análise do som}

O microfone dinâmico e o captador piezoelétrico, captaram os sons durante os testes de percussão, nos pisos sem e com patologia e o "software" Realtime Analyzer registrou e produziu gráficos. Inicialmente, houve demarcação de reações em todas as placas com a finalidade de reproduzir a ocorrência dos choques nos mesmos lugares.

Os gráficos apontam para a relação entre amplitude de frequência x pressão sonora ${ }^{3} \mathrm{x}$ tempo, representados pelas unidades de medidas Hertz $(\mathrm{Hz})$ x decibel $(\mathrm{dB})$ x segundo (s), respectivamente. O canal esquerdo (Lch), mostrado na parte superior dos gráficos é a representação do espectro do som captado pelo microfone dinâmico, já o canal direito (Rch) na parte inferior dos gráficos reproduz o captador piezoelétrico.

Comparando os gráficos do som gerado ao percutir a P5s e P5c pelo protótipo, nota-se que a placa assentada sem patologia, P5s (Fig. 6a), exibe uma grande faixa de frequência bem definida entre $4 \mathrm{kHz}$ até os $15 \mathrm{kHz}$ no Lch, constata-se também um crescimento e atenuação nesse mesmo intervalo e com pico em 6 kHz. A placa assentada com patologia, P5c (Fig. 6b) possui atenuação da banda de frequência entre $4 \mathrm{kHz}$ até os $15 \mathrm{kHz}$ e maior amplitude no grave e entre os intervalos de $1,5 \mathrm{kHz}$ até $2 \mathrm{kHz}$ no Lch, já no Rch percebe-se um crescimento da amplitude nas regiões entre $100 \mathrm{~Hz}$ até $400 \mathrm{~Hz}$ e de $1,5 \mathrm{kHz}$ até $2,5 \mathrm{kHz}$.

As Fig. 6c e 6d retratam o teste de impacto utilizando o protótipo demonstrado pelo espectrograma ${ }^{4}$. Na P5s (Fig. 6c) é possível identificar definições nas faixas de frequência colhidos pelo microfone dinâmico e pelo catador piezoelétrico. Outra característica é a homogeneização das gamas de frequência durante todos os choques. Já na P5c (Fig. 6d), as frequências gravadas pelo Lch possuem um traçado menos definido, pois há uma mudança no domínio da frequência no decorrer dos impactos, outro dado é a amplitude do som captado que é ligeiramente maior em um curto intervalo de tempo.

\footnotetext{
${ }^{3}$ Nos gráficos o grau de potência da onda sonora é representado por SPL (Sound Pressure Level).

${ }^{4}$ Espectrogramas são gráficos que analisam dinamicamente a densidade espectral de energia. Os valores são indicados no plano tempo x frequência e com diferentes cores para indicar a intensidade da densidade espectral de energia, variando do violeta ao vermelho do espectro visível.
} 


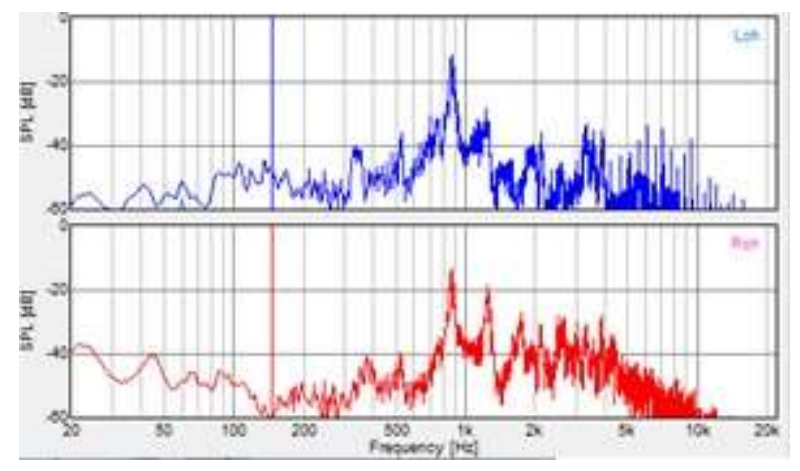

a)
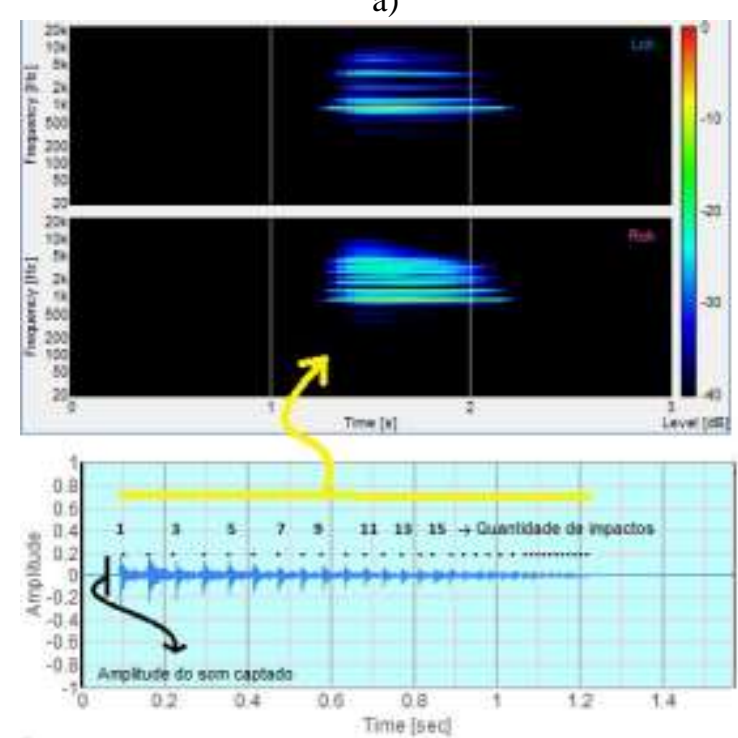

c)

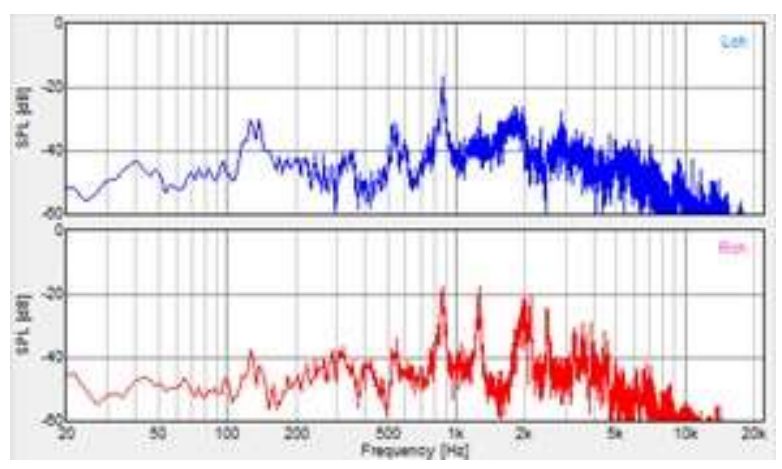

b)
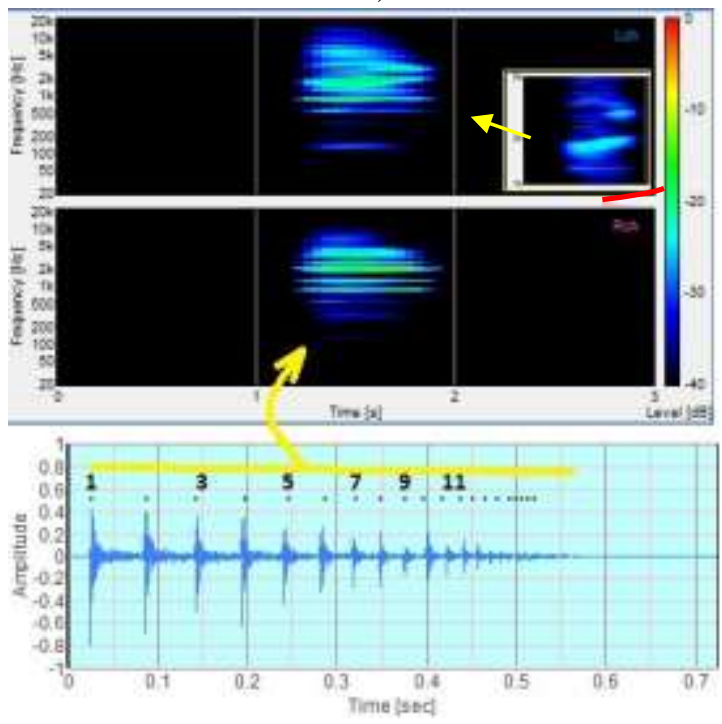

d)

Figura 6: Gráficos representando o resultado ao percutir dois pisos cerâmicos com o protótipo: a) e c) sem patologia, b) e d) com patologia

Confrontando os gráficos processados, ao percutir a P5s e P5c por um cabo de madeira, constata-se que a placa assentada sem patologia, P5s (Fig.7a) detém maiores amplitude nas faixas de frequência entre $200 \mathrm{~Hz}$ e 6,3kHz. A placa assentada com patologia, P5c (Fig.7b), também possui maiores representações no intervalo de média frequência. Porém, os picos de frequência estão mais deslocados para a esquerda, em direção do grave. Nota-se ainda um aumento da amplitude entre $100 \mathrm{~Hz}$ até $400 \mathrm{~Hz}$.

Os espectrogramas das Fig.7c e 7d apresentam o impacto da madeira na P5s e P5c respectivamente. Percebem-se definições nas faixas de frequência registrada pelo microfone dinâmico e captador piezoelétrico em ambas as placas. Também é possível constatar semelhança no tempo de impacto e dos picos de frequência captados nos (Rch) e (Lch). 


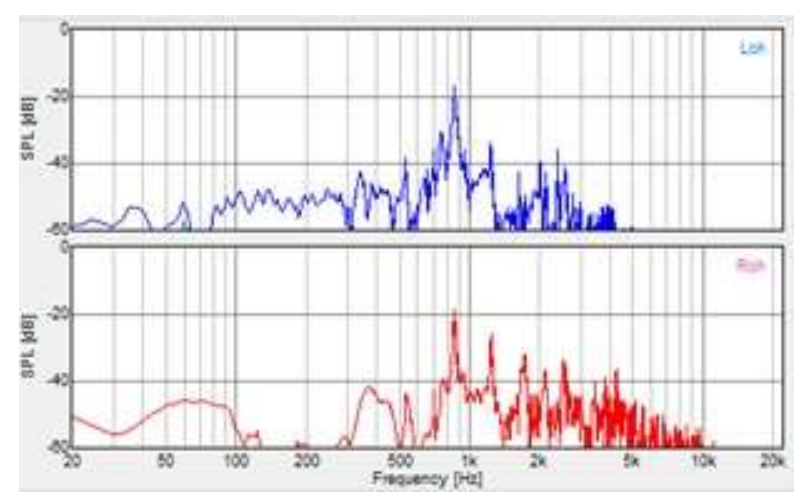

a)

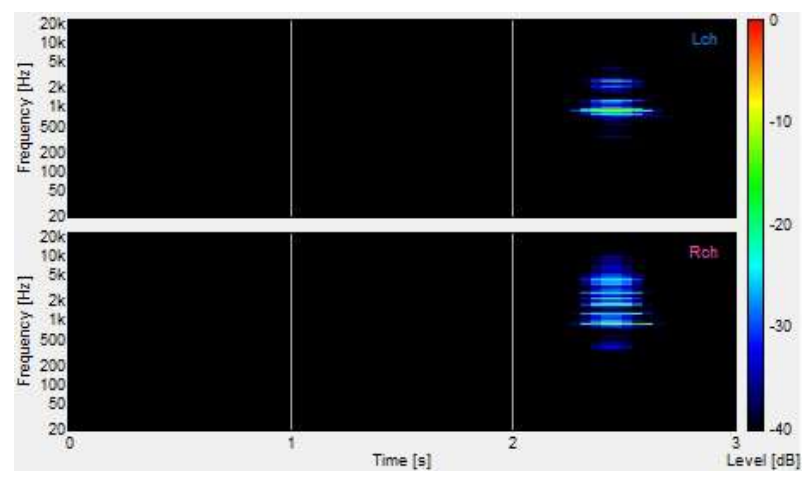

c)

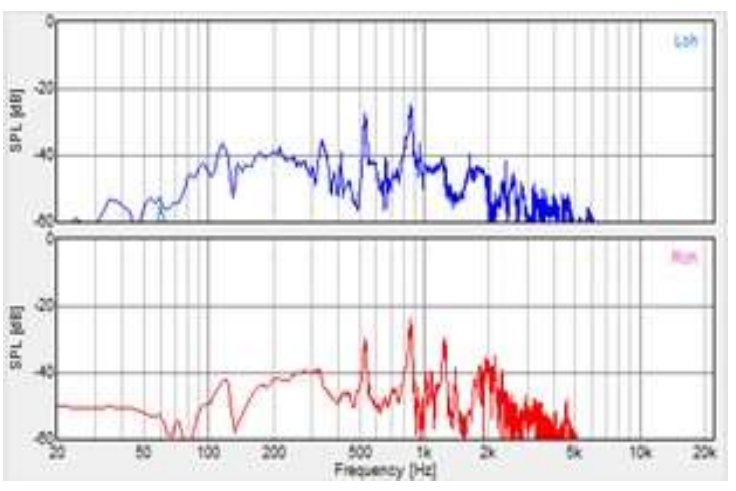

b)

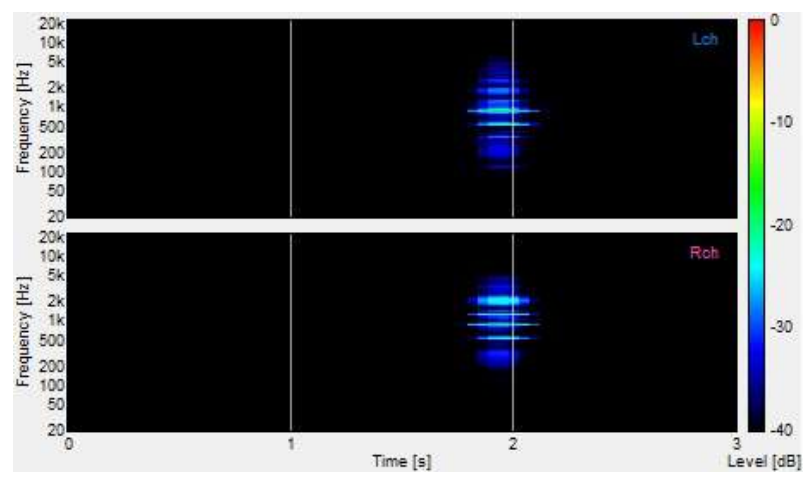

b)

Figura 7: Gráficos representando o resultado ao percutir dois pisos cerâmicos com um cabo de madeira: a) e c) piso sem patologia b) e d) pisos com patologia.

Relacionando os gráficos ao impactar a esfera em P5s e P5c, constata-se que, tanto a Fig. 8a quanto a 8 b detêm maior representatividade das amplitudes nas faixas de frequência entre $200 \mathrm{~Hz}$ e $6,3 \mathrm{kHz}$. Todavia, a Fig. 8b possui vários picos de frequência deslocada para o grave, atenuação para o agudo e um aumento da intensidade entre $1,5 \mathrm{kHz}$ até $1,9 \mathrm{kHz}$.

Analisando o espectrograma da Fig. 8c e 8d, que representam o choque da esfera na P5s e P5c respectivamente, percebem-se linhas bem definidas no traço das gamas de frequência captadas pelo microfone dinâmico e captador piezoelétrico nos dois testes. Durante os ensaios, foi possível ouvir pelo timbre que os impactos produziram a mesma intensidade durante todos os primeiros choques.

Destaca-se que o registro em amplitude do volume sonoro produzido pela esfera é o menor entre todos os métodos, comprovando que, quanto maior o coeficiente de restituição, nesse caso a esfera, menor será a energia sonora produzida.

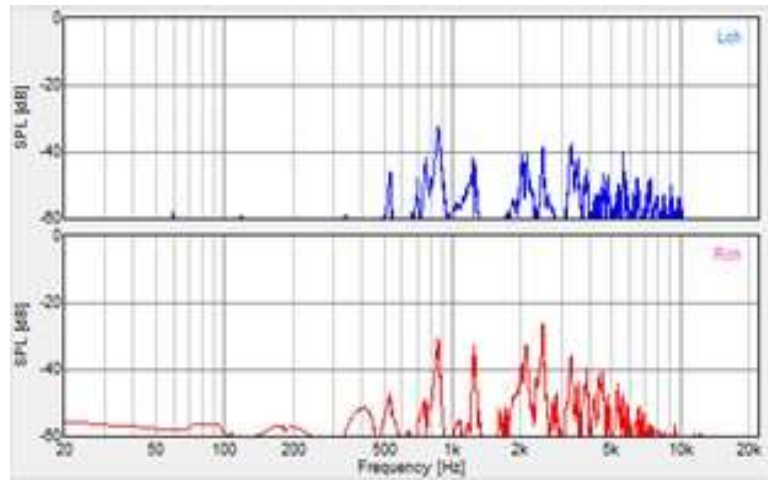

a)

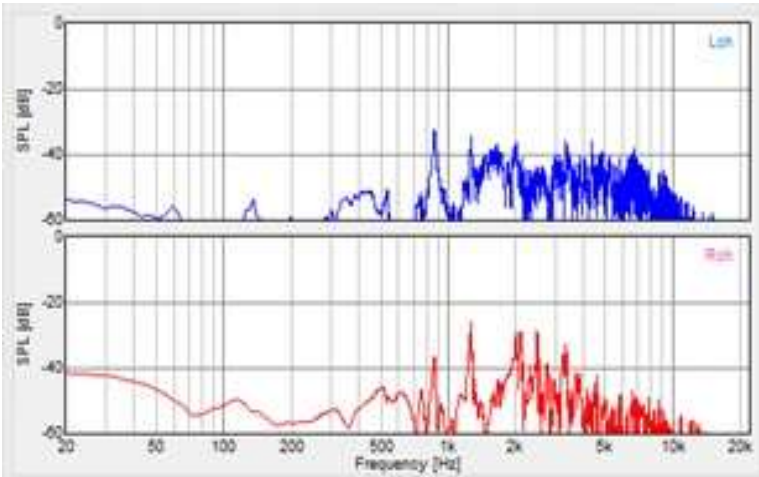

b) 


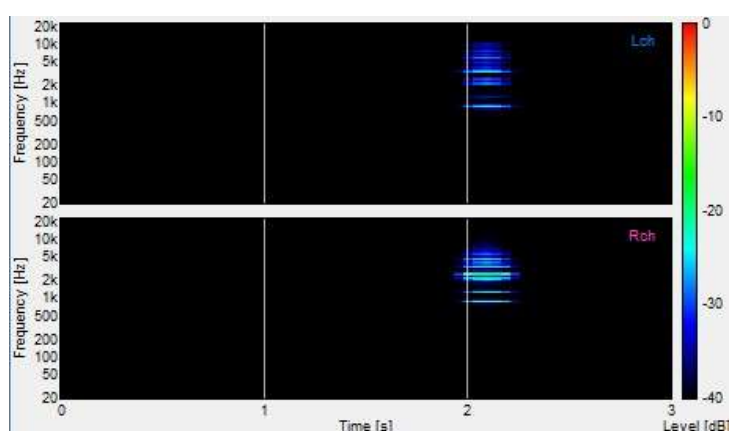

c)

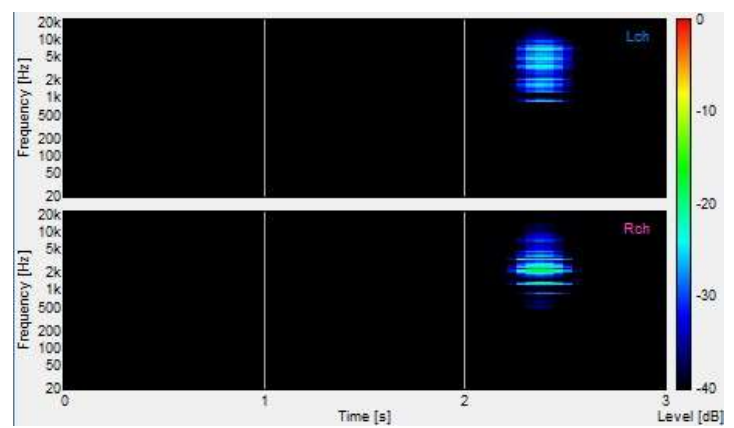

d)

Figura 8: Gráficos representando o resultado ao percutir dois pisos cerâmicos com a esfera: a) e c) pisos sem patologia, b) e d) pisos com patologia.

Verificando-se os gráficos produzidos ao percutir a P5s e P5c pela barra roscada (Fig.9a e 9b), nota-se que ambas as placas assentadas dispõem de uma grande gama de frequência, entre $300 \mathrm{~Hz} \mathrm{a} 11 \mathrm{kHz}$ e atenuação na frequência dos agudos no Rch. No entanto, na P5c o Lch possui uma atenuação na faixa dos sons agudos, e um aumento da amplitude entre $150 \mathrm{~Hz}$ a $300 \mathrm{~Hz}$ e $1,5 \mathrm{kHz}$ a $2 \mathrm{kHz}$.

As Fig. 9c e 9d ilustram o espectrograma do impacto da barra roscada nas P5s e P5c, respectivamente. Distinguem-se definições e linearidades do traço das frequências em ambos os ensaios.

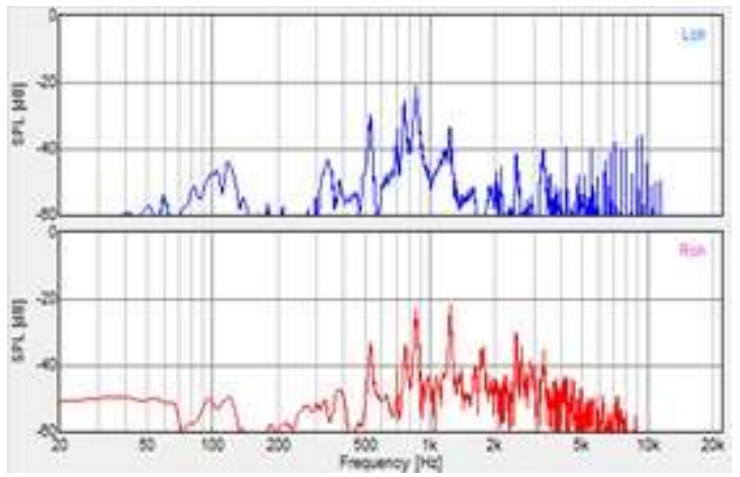

a)

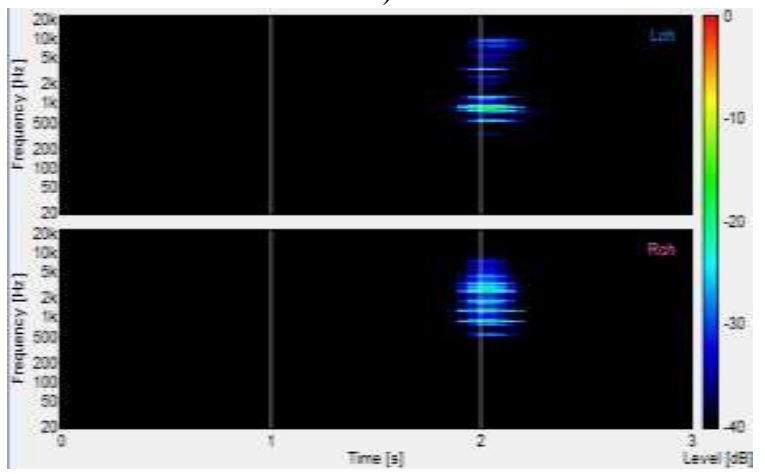

c)

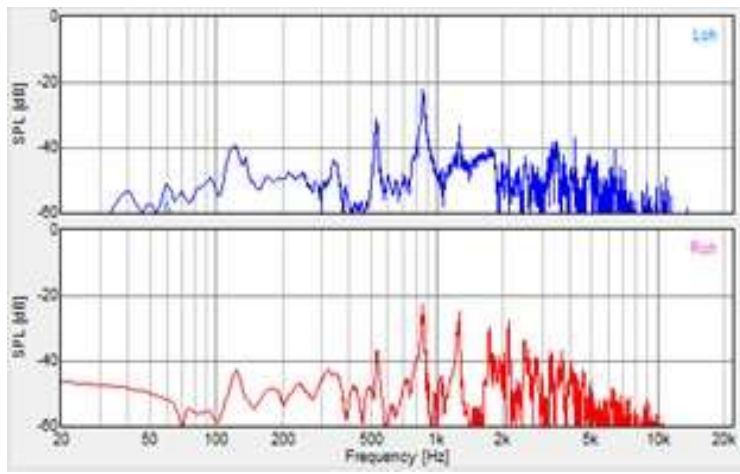

b)

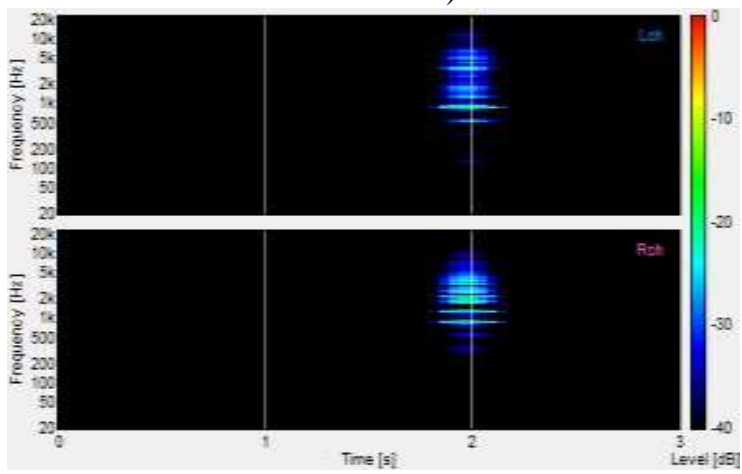

d)

Figura 9: Gráficos representando o resultado ao percutir dois pisos cerâmicos com a barra roscada: a) e c) pisos sem patologia, b) e d) pisos com patologia.

Equiparando os gráficos ao impactar a P5s e P5c pela barra (Fig.10a e 10b), nota-se que ambas as placas assentadas dispõem de um grande intervalo de frequência, desde $20 \mathrm{~Hz}$ a $16 \mathrm{kHz}$, aumento da amplitude nos intervalos entre $100 \mathrm{~Hz}$ a $400 \mathrm{~Hz}$ e $1,5 \mathrm{kHz}$ a $2 \mathrm{kHz}$, e atenuação na frequência dos agudos no Rch.

As Fig. 10c e 10d exibem o espectrograma do choque da barra de aço nas P5s e P5c, respectivamente. É possível destacar definições dos picos de frequências nas placas captada por ambos os canais. 


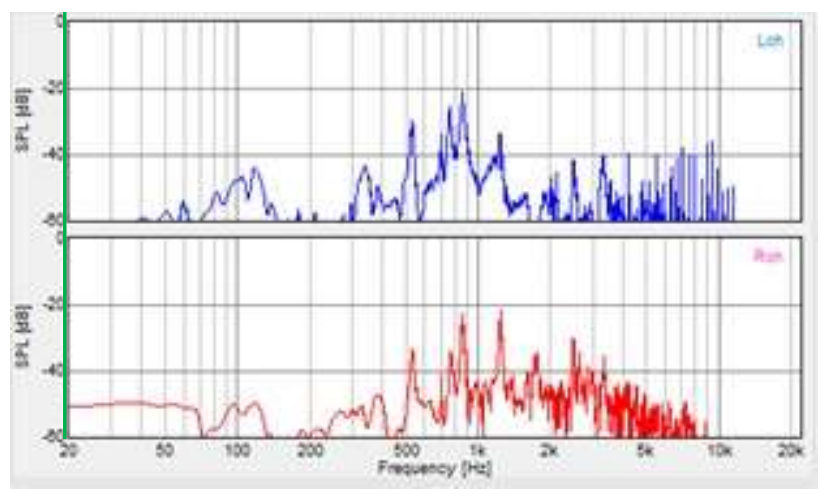

a)

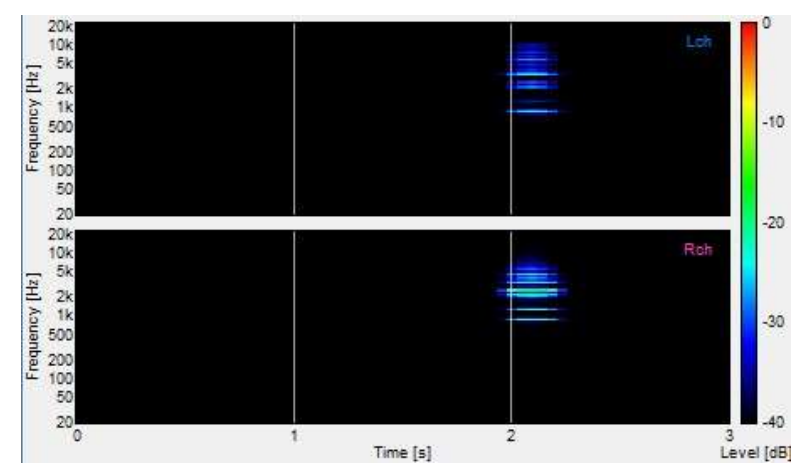

c)

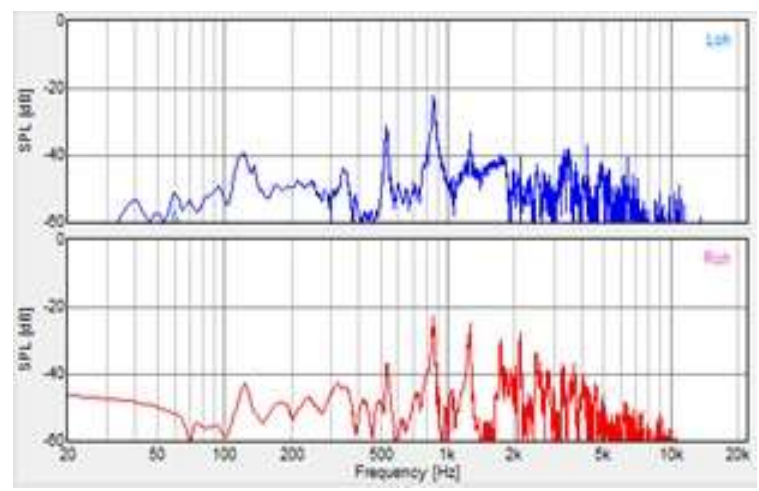

b)

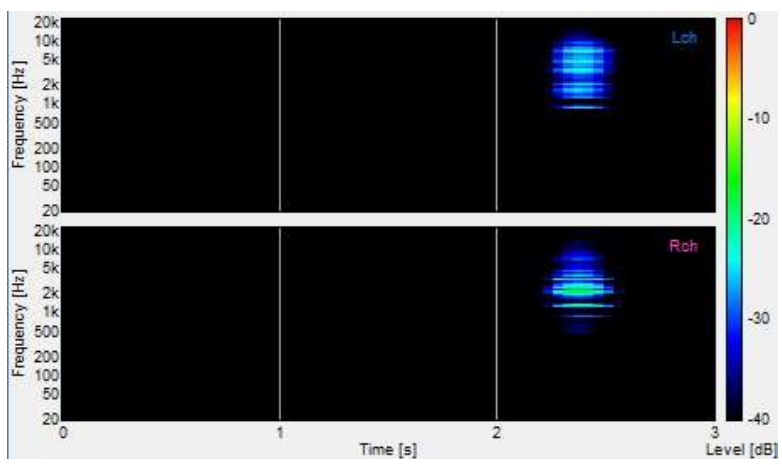

d)

Figura 10: Gráficos representando o resultado ao percutir dois pisos cerâmicos com a barra de aço: a) e c) pisos sem patologia, b) e d) pisos com patologia.

\section{DISCUSSÃO}

\subsection{Coeficiente de restituição}

Observando os resultados de coeficientes de restituição Tab. 3, percebe-se que a P3s é a que possui o maior coeficiente de restituição em todos os ensaios. Tal fato é explicado devido à natureza do material, um porcelanato com baixa porosidade e maior espessura, confirmando o trabalho de MUELLER et al. [20], o qual afirma que a porosidade das partículas aumenta a dissipação de energia devido a um amortecimento ligeiramente maior.

Pode-se concluir desses resultados que alguns fatores influenciam no coeficiente de restituição:

- Comparando a P1s e P4s verifica-se que a espessura do piso influencia no coeficiente de restituição. Esses dois pisos possuem características similares, mudando somente a espessura, confirmando algumas pesquisas da área os quais afirmam que com o aumento da espessura, maior será a resposta ao choque e, consequentemente maior o coeficiente de restituição [20, 21, 22].

- Comparando P5s e P6s, constata-se que o grupo de absorção influenciou no coeficiente de restituição, mas não de maneira muito significativa, confirmando estudos anteriores [20].

- Comparando P1s e P2s percebemos que o piso antiderrapante influenciou no coeficiente de restituição, diminuindo para a esfera e aumentando para as barras. A explicação para esse fato é a superfície de impacto, $\mathrm{O}$ trabalho de [23] concluiu que os pisos antiderrapantes possuem saliências que diminuem a superfície de contato. Já nos pisos lisos há um aumento da área de contato. Não obstante, no caso da esfera, ocorre o contrário: as irregularidades aumentam a área de superfície.

\subsection{Análise do som}

Com base nos resultados da análise do som, algumas considerações são apresentadas:

A esfera é de difícil manuseio, pois após o rebote, frequentemente, ela extrapola as proximidades das placas. 
Verifica-se que o cabo de madeira produz um espectro com menor faixa de frequência entre os métodos em pisos com e sem patologia, visto que ao impactar com um material rígido, rapidamente a madeira passou do regime elástico para o plástico, ocorrendo o amortecimento.

Em todos os métodos, a amplitude do som captado com o microfone dinâmico era maior nos pisos com patologia e nos pisos sem patologia, o captador piezoeléctrico foi o que demostrou maiores amplitudes, esse fato pode ser explicado pela energia dissipada no choque, como no piso sem patologia há uma maior conservação de energia o captador piezoeléctrico irá capar as ondas de choque, já o piso com patologia por possuir grande perda de energia será convertida em energia acústica, ou seja, o som sempre terá maiores amplitudes nesses choques.

Constatou-se em todos os métodos que, ao impactar um mesmo objeto com um piso sem patologia e outro com patologia, o piso com a anomalia apresentará picos de frequências deslocadas para a esquerda em direção do grave.

Os pisos sem patologia sempre apresentaram baixa amplitude em um longo período de tempo a uma taxa constante, já os pisos com patologia apresentaram maiores amplitudes em um curto intervalo de tempo.

Em relação ao manuseio do cabo de madeira e das barras, percebe-se a dificuldade em mantê-las verticalmente, porque após o primeiro impacto havia a tendência de rotação. O operador deve ter cuidado para não interagir com os objetos durante os movimentos ascendentes e descendentes dos objetos. Por várias ocasiões foi necessário repetir os ensaios, por conta dessa interferência.

A estrutura do tripé do protótipo permite que este se mantivesse apoiado sobre os pisos cerâmicos durante os ensaios.

O protótipo necessitou somente de um movimento de deformação, uma vez que ao liberar a barra móvel, o amortecedor elástico permite seu próprio movimento.

Os gráficos da utilização do protótipo foram os melhores, em que os picos de frequência foram similares em todos os rebotes e o intervalo de tempo entre um e outro era menor, proporcionando uma percepção de som contínuo ao impactar com o piso sem patologia. Já no piso que apresentava patologia ocorreu uma leve variação do domínio da amplitude no tempo, possibilitando uma percepção diferenciada.

De posse dos resultados, observa-se que o protótipo é eficiente na detecção da patologia estudada, apresentando vantagens em relação ao manuseio e à percepção da resposta cinética e acústica.

\section{CONCLUSÃO}

Esse trabalho propôs o desenvolvimento e a experimentação de um protótipo para verificar a patologia de mal assentamento de pisos cerâmicos. O protótipo é um instrumento de baixo custo, de fácil reprodução e manipulação, e foi baseado em uma metodologia não destrutiva que produz um som cavo após impacto de pequena intensidade no piso cerâmico com perda de aderência.

A análise espectral e temporal mostra que a resposta acústica do protótipo foi melhor em relação aos outros quatro métodos não normatizados: esfera, cabo de madeira, barra de aço e barra roscada. Ao impactar o percursor do protótipo com o piso mal assentado obteve-se como resposta um som audível com variação no domínio da frequência em um curto período de tempo, possibilitando uma distinção entre pisos com ou sem patologia.

Após a realização dos ensaios, comprovou-se que o uso do protótipo é viável para a detecção de patologia de assentamento das placas cerâmicas, revelando ser uma estratégia preventiva e não destrutiva, podendo ser facilmente utilizado durante a inspeção e verificação de conformidades.

\section{BIBLIOGRAFIA}

[1] BENTO, J.J.J. Patologias em revestimentos cerâmicos colados em paredes interiores de edifícios, Dissertação M.Sc., Universidade do Porto, Portugal, 2010.

[2] SILVA, T. P., FIGUEIREDO, M. O., PRUDÊNCIO, M. I. “Ascertaining the degradation state of ceramic tiles: a preliminary non-destructive step in view of conservation treatments", Applied Clay Science, v. 82, pp. 101-105, 2013.

[3] VILLELA T. R. Análise comparativa do desempenho, produção e manutenção de revestimentos cerâmicos em pisos. Monografia, Universidade Federal de Minas Gerais (UFMG), Belo Horizonte, 2015.

[4] DiÓGENES, H. J. F., COSSOLINO, L. C., PEREIRA, A. H. A., et al., "Determinação do módulo de elasticidade do concreto a partir da resposta acústica", Revista Ibracom de estruturas e materiais, v. 4, n. 5, pp. 792-813, Dez. 2011. 
[5] ASSOCIAÇÃO BRASILEIRA DE NORMAS TECNICAS (ABNT). NBR 9817. Execução de piso com revestimento cerâmico - Procedimento. Rio de Janeiro, 1987.

[6] ASSOCIAÇÃO BRASILEIRA DE NORMAS TECNICAS (ABNT). NBR 13.753. Revestimento de piso interno ou externo com placas cerâmicas e com utilização de argamassa colante - Procedimento. Rio de Janeiro, 1996.

[7] AZEVEDO, A.R.G., ALEXANDRE, J., ZANELATO, E.B., et al., "Influence of incorporation of glass waste on the rheological properties of adhesive mortar", Construction and Building Materials, v. 148, n.1, pp. 359-368, 2017.

[8] AZEVEDO, A.R.G., ALEXANDRE, J., XAVIER, G.C., et al., "Evaluation of a Tacking Stage for Adherence, between Mortar and Ceramic Brick", Materials Science Forum (Online), v. 869, pp. 121-126, 2016.

[9] LACZÁK, L. E., KÁROLYI, G. "On the impact of a rigid-plastic missile into rigid or elastic target", International Journal of Non-Linear Mechanics, v. 91, pp. 1-7, 2017.

[10] NIKNAMI, A., SHARIYAT, M. "Refined constitutive, bridging, and contact laws for including effects of the impact-induced temperature rise in impact responses of composite plates with embedded SMA wires", Thin-Walled Structures, v. 106, pp. 166-178, 2016.

[11] MCLASKEY, G. C., GLASER, S. D. "Hertzian impact: Experimental study of the force pulse and resulting stress waves", The Journal of the Acoustical Society of America, v. 128, n. 3, pp. 1087-1096, 2010.

[12] ASSOCIAÇÃO BRASILEIRA DE NORMAS TECNICAS (ABNT). NBR 14.081. Argamassa colante industrializada para assentamento de placas cerâmicas - Requisitos. Rio de Janeiro, 2012.

[13] ARYAEI, A., HASHEMNIA, K., JAFARPUR, K. "Experimental and numerical study of ball size effect on restitution coefficient in low velocity impacts", International Journal of Impact Engineering, v. 37, n. 10, pp. 1037-1044, 2010.

[14] WU, C. Y., LI, L.Y., THORNTON, C. "Energy dissipation during normal impact of elastic and elasticplastic spheres", International Journal of Impact Engineering, v. 32, n. 1, pp. 593-604, 2005.

[15] INTERNATIONAL ORGANIZATION FOR STANDARDIZATION. ISO 10545-5. Ceramic tiles - Part 5: Determination of impact resistance by measurement of coefficient of restitution, 2002.

[16] HORABIK, J., BECZEK, M., MAZUR, R., et al., "Determination of the restitution coefficient of seeds and coefficients of visco-elastic Hertz contact models for DEM simulations", Biosystems Engineering, v. 161, pp. 106-119, 2017.

[17] LI, T., ZHANG, J., GE, W. "Simple measurement of restitution coefficient of irregular particles", China Particuology, v. 2, n. 6, pp. 274-275, 2004.

[18] JIANG, S., SHEN, L., GUILLARD, F., et al., "Energy dissipation from two-glass-bead chains under impact", International Journal of Impact Engineering, v. 114, pp 160-168, 2018.

[19] PERTUZZATTI, A., CONTE, B., MISSIO, A. L., et al., "The Influence of Moisture in Bending Strength of Eucalypt Wood", Floresta e Ambiente, v. 24, pp. 1-6, 2017.

[20] MUELLER, P., BOETTCHER, R., RUSSELL, A., et al., "A novel approach to evaluate the elastic impact of spheres on thin plates", Chemical Engineering Science, v. 138, pp. 689-697, 2015.

[21] FARIN, M., MANGENEY, A., ROSNY, J., et al., "Experimental validation of theoretical methods to estimate the energy radiated by elastic waves during an impact", Journal of Sound and Vibration, v. 362, pp. 176-202, 2016.

[22] DONDI, M., GUARINI, G., MELANDRI, C., et al., "Resistance to impact of porcelain stoneware tiles", Ceramics International, v. 42, n. 5, pp. 5731-5736, 2016.

[23] ADAMS, G. G., NOSONOVSKY, M. "Contact modeling-forces", Tribology International, v. 33, n. 5, pp. 431-442, 2000.

\section{ORCID}

Diogo Florencio Pessanha

Jonas Alexandre

José Augusto Pedro Lima

Afonso Rangel Garcez de Azevedo

Euzebio Bernabe Zanelato https://orcid.org/0000-0003-0265-8351

https://orcid.org/0000-0002-2977-5585

https://orcid.org/0000-0001-9760-3032

https://orcid.org/0000-0002-4694-4459

https://orcid.org/0000-0002-3824-0195 